\title{
KEEFEKTIFAN PENGGUNAAN BUKU AJAR MATA KULIAH APRESIASI DAN KAJIAN DRAMA BERBASIS KEBUDAYAAN BREBES
}

\author{
Ghufroni $^{1}$, Prasetyo Yuli Kurniawan ${ }^{2}$, Robert Rizki Yono ${ }^{3}$, M Wildan Arvin Hakim ${ }^{4}$ \\ ${ }^{1}$ Prodi Pendidikan Bahasa dan Sastra Indonesia, Fakultas Keguruan dan Ilmu Pendidikan, Universitas \\ Muhadi Setiabudi Brebes, Indonesia, ${ }^{2}$ Prodi Pendidikan Bahasa dan Sastra Indonesia, Fakultas \\ Keguruan dan Ilmu Pendidikan, Universitas Muhadi Setiabudi Brebes, Indonesia, ${ }^{3}$ Prodi Pendidikan \\ Bahasa dan Sastra Indonesia, Fakultas Keguruan dan Ilmu Pendidikan, Universitas Muhadi Setiabudi \\ Brebes, ${ }^{4}$ Prodi Pendidikan Bahasa dan Sastra Indonesia, Fakultas Keguruan dan Ilmu Pendidikan, \\ Universitas Muhadi Setiabudi Brebes, Indonesia \\ e-mail: *1 ghufronironi@gmail.com, ${ }^{2}$ prasetyoyulikurniawan@gmail.com, \\ 3 robertrizkiyono@gmail.com, \\ 4 anjaykomikawal@gmail.coj
}

\begin{abstract}
ABSTRAK
Penelitian ini bertujuan untuk mendeskripsikan penggunaan buku ajar dalam perkuliahan Apresiasi dan Kajian Drama Berbasis Kebudayaan Brebes dan menguji keefektifan buku Apresiasi dan Kajian Drama bagi mahasiswa pendidikan bahasa dan sastra Indonesia. Metode penelitian ini menggunakan metode eksperimen dengan model penelitian one group pretest-postest design. Jenis eksperimen ini menggunakan satu kelas dengan perlakuan tes awal sebelum dilakukan eksperimen. Hasil penelitian ini menunjukan bahwa nilai awal (pretest) terdapat nilai yang belum tuntas sebanyak 20 mahasiswa dan nilai akhir (postest) tuntas semua. Hasil uji keefektifan penggunaan buku ajar berdasarkan tabel independent samples test menyatakan adanya perbedaan signifikan hasil pretest dan postest. Dengan demikian, buku ajar mata kuliah Apresiasi dan Kajian Drama Berbasis Kebudayaan Brebes efektif digunakan dalam perkuliahan.
\end{abstract}

Kata kunci: Buku ajar, Kebudayaan Brebes, Metode eksperimen.

\begin{abstract}
This study aims to describe the use of textbooks in the Brebes Culture Appreciation and Drama Study lectures and examine the effectiveness of the Book of Appreciation and Drama Studies for Indonesian language and literature education students. This research method uses an experimental method with a one group pretest-posttest design research model. This type of experiment uses one class with the initial test treatment before the experiment is carried out. The results of this study indicate that the initial value (pretest) there is an incomplete value of 20 students and the final value (posttest) all completed. The effectiveness test results of the use of textbooks based on the independent samples test table revealed a significant difference in the results of the pretest and posttest. As such, the Brebes Culture Based Appreciation and Drama Textbooks are effectively used in lectures.

Keywords: , Textbooks, Brebes Cultur, Methode Ekspreriment,
\end{abstract}

\section{PENDAHULUAN}

Sebagai seorang dosen dalam memberikan meteri pembelajaran harus menarik bagi mahasiswa. Materi tersebut disusun dengan menggunakan berbagai pendekatan. Misalnya dengan menggunakan media, model, maupun bahan ajar tertentu. Media pembelajaran adalah alat bantu proses pembelajaran yang dipergunakan untuk menyampaikan pesanpesan atau informasi pembelajaran sehingga dapat merangsang pikiran, perhatian, perasaan, dan keterampilan belajar sehingga dapat mendorong terjadinya proses belajar yang baik [1]. Media pembelajaran harus tersusun secara sistematis dan menyenangkan. Salah satu membuat pembelajaran yang menyenangkan dengan menyusun bahan ajar yang menyenangkan pula. Bahan ajar merupakan salah satu perangkat pembelajaran yang terdiri dari pengetahuan, sikap, dan keterampilan yang dikembangkan berdasarkan standar 
Jurnal Ilmiah SEMANTIKA, Volume 2, No. 01, Agustus 2020, p. 36-43

kompetensi lulusan (SKL), standar kompetensi (SK), dan kompetensi Dasar (KD) pada kurikulum yang harus dipelajari oleh mahasiswa dalam rangka mencapai kompetensi yang ditentukan [2].

Salah satu keberhasilan dosen dalam mengajar ditentukan oleh pemilihan media. Media belajar yang dipilih dapat ditentukan ke dalam lima kategori 1) Manusia dan benda nyata 2) Media visual proyeksi 3 ) Media audio 4) Media cetak 5) Media display [3]. Buku adalah salah satu dari media yang bisa dipilih sebagai media pembelajaran, karena buku adalah seperangkat materi yang disusun secara sistematis sehingga tercipta suasana dan lingkungan belajar yang baik dan nyaman. Buku yang yang berkualitas adalah buku yang mambantu mengantarkan belajar dalam memperoleh pengetahuan secara kognitif, afektif dan psikomotorik. Dosen perlu mengemas media tersebut dalam pembelajaran disesuaikan dengan kebutuhan matakuliah yang akan diajarkan misalnya mata kuliah apresiasi dan kajian drama.

Matakuliah apresiasi dan kajian drama merupakan bagian dari ilmu sastra yang membahas tentang unsur-unsur dan struktur drama. Drama memiliki keistimewaan tersendiri dibandingkan dengan genre sastra lain. Drama memberikan ruang kebebasan pada pengarang atau pembaca untuk berimajinasi dan drama diciptakan untuk dipentaskan dan dinikmati secara bersama-sama [4]. Berdasarkan hasil observasi yang telah dilakukan pada mahasiswa pendidikan bahasa dan sastra Indonesia di Universitas Muhadi Setiabudi, mahasiswa belum memahami dan menggauli secara mendalam. Hal ini dibuktikan mahasiswa belum mampu mempraktekkan dari mulai persiapan awal sampai pada pementasan. Selain itu masih terbatasnya sumber pustaka yang dijadikan sebagai bahan referensi bagi mahasiswa. Bahkan buku yang kaitanya dengan drama tidak ditemukan, sehingga perlunya bahan ajar mata kuliah apresiasi dan kajian drama agar mahasiswa kaya akan pengetahuan dan pengalaman serta mempraktikkan.

Selain itu bahan ajar juga mengandung nilai-nilai tertentu, agar tidak hanya memperoleh kompetensi paedagogik, tetapi juga nilai afektif yang dilandasi nilai luhur dan budi pekerti. Nilai-nilai yang diterapkan pada mahasiswa adalah nilai kebudayaan. Fenomena dimasa sekarang nilai kebudayaan mulai luntur karena budaya asing yang dikemas dalam bentuk sosial media yang lebih menarik. Dunia pendidikan diharapkan mampu berperan aktip dalam menanamkan kebudayaan terutama kebudayaan Brebes. Dalam hal ini Universitas Muhadi Setiabudi mempunyai tanggungjawab dalam mengembangkan nilai budaya bagi mahasiswa sesuai dengan misi dalam rencana Pembangunan Jangka Panjang (RPJP) daerah kabupaten Brebes tahun 2005-2025 yaitu sebagai berikut:

"Mewujudkan pengenalan nilai-nilai agama dan kearifan lokal. Makin kuatnya karakter masyarakat yang berbasis pada agama dan nilai-nilai budaya, sehingga menjadi manusia-manusia yang beriman, bertakwa kepada tuhan YME, berakhlak mulia, bermoral, beretika berdasarkan pada falsafah pancasila, yang akhirnya mampu berpikir, bersikap dan bertindak sebagai manusia yang tangguh, kompetitip, berbudi luhur, bertoleransi, bergotong royong, berjiwa patriotik, menunjang nilai-nilai luhur budaya bangsa, mengedepankan kearifan lokal dan selalu berkembang secara dinamis [5].

Atas dasar itulah, perlu dikembangkan pembelajaran yang berbasis kebudayan Brebes agar mahasiswa di Universitas Muhadi Setiabudi disamping memperoleh materi tentang apresiasi drama yang dikemas dengan mengedepankan kemampuan praktik dalam bentuk buku pembelajaran, juga memperoleh pembelajaran berbasis kebudayaan. Pembelajaran berbasis kebudayaan bertujuan untuk membudayaan sikap, pengetahuan, keterampilan dan tradisi yang ada dalam suatu komunitas budaya, serta untuk mengembangkan budaya dalam suatu komunitas melalui pencapaian akademik siswa. [6] Mahasiswa juga memperoleh pengetahuan kebudayaan Brebes sebagaimana menjadi tujuan pemerintah Brebes. Oleh 
Jurnal IImiah SEMANTIKA, Volume 2, No. 01, Agustus 2020, p. 28-35

karena itu penelitian ini akan menguji keefektifan buku ajar apresiasi dan kajian drama yang berbasis kebudayaan Brebes, sejauh mana buku ajar dapat menunjang perkuliahan dan nilainilai budaya bagi mahasiswa.

Salah satu aspek bahan ajar dalam pembelajaran adalah ketersediaan buku ajar sebagai penunjang pembelajaran. Biasanya buku ajar bersifat mandiri, artinya dapat dipelajari mahasiswa secara mandiri karena sistematis dan lengkap [7]. Buku ajar yang sistematis digunakan mahasiswa dan dosen digunakan dalam perkuliahan yang terstruktur dengan menjelaskan tujuan instruksional yang akan dicapai, memotivasi untuk belajar, memuat latihan (evaluasi), dan menyadiakan rangkuman pembelajaran. Buku ajar juga harus mempertimbangkan kriteria-kriteria yang meliputi (1) relevansi (Secara psikologis maupun sosiologis), (2) kompleksitas, (3) rasional ilmiah, (4) fungsional, (5) ke-up to date-an (6) komprehenship/keseimbangan [8].

Salah satu bentuk karya sastra adalah drama. Drama sebagai karya sastra merupakan objek terikat pada pengarang, realitas dan penikmat. Drama berasal dari bahasa Yunani Dram yang berarti gerak, Drama merupakan genre (jenis) karya sastra yang menggambarkan kehidupan manusia dengan gerak. Drama menggambarkan realitas kehidupan, watak serta tingkah laku manusia melalui peran yang dipentaskan [9]. Kisah dan cerita drama menggambarkan konflik dan emosi dalam pementasan drama. Kisah drama dapat menggambarkan kualitas drama melalui naskah drama yang disusun oleh penulis drama yang bisa dibuktikan dalam pementasan drama.

Penelitian ini berpijak dari penelitian sebelumnya. Salah satu penelitian yang dijadikan pustaka yaitu penelitian yang dilakukan oleh Sutrisno (2018) dengan judul "Efektifitas Buku Ajar Matematika SMP Berbasis 3-D untuk meningkatkan komunikasi Matematis Siswa". Penelitian tersebut bertujuan untuk mengetahui efektifitas buku ajar matematika SMP berbasis 3-D untuk meningkatkan kemampuan komunikasi matematis siswa. Hasil penelitian menunjukkan bahwa buku ajar matematika SMP berbasis 3-D untuk meningkatkan kemampuan komunikasi matematis siswa efektif digunakan sebagai proses pembelajaran. Relevansi penelitian yang dilakukan Sutrisno dengan penelitian ini ada persamaan dan perbedaan. Persamaanya terletak pada variabel yang diuji kefektifanya yaitu buku ajar, sedangkan perbedaanya terletak pada subjek penelitian. Jika penelitian yang dilakukan oleh Sutrisno yaitu kepada siswa, sedangkan penelitian ini ditujukan kepada mahasiswa Universitas Muhadi Setiabudi.

Penelitian ini juga relevan dengan artikel Parris (2010) dengan jurnal artikel "Cultural Dimension of Learning: Addressing The Challanges of Multicultural Instruksional" Volume 11 No. 2 (2010) memaparkan bahwa pembelajaran berbasis kebudayaan sangat diperlukan bagi peserta didik. Dengan menerapkan budaya dalam pembelajaran secara tidak langsung mengajarkan sikap cinta kebudayaan, menerapkan sikap karakter kebangsaan dan menanamkan cinta tanah air. Karena pembelajaran berbasis kebudayaan, implikasinya dapat mengenalkan potensi daerahnya dan secara langsung mengenalkan budaya sendiri. Pembelajaran berbasis kebudayaan juga menanamkan sikap tenggang rasa sesama, peduli pada lingkungan dan menghormati perbedaan latar belakang. Jadi artikel yang ditulis oleh Parris untuk menguatkan penerapan nilai budaya dalam pengembangan buku ajar mata kuliah apresiasi dan kajian drama berbasis kebudayaan Brebes.

\section{METODOLOGI PENELITIAN}

Penelitian ini menggunakan metode eksperimen. Penelitian eksperimen dapat diartikan sebagai metode penelitian yang digunakan untuk mencari pengaruh perlakukan tertentu terhadap yang lain dalam kondisi yang dikendalikan [10] Populasi penelitian ini adalah mahasiswa semester 3 program Studi Pendidikan Bahasa dan Sastra Indonesia, sedangkan jenis eksperimen pada penelitian ini yaitu pre-eksperiment dengan desain One Shot Preetest posttest. 
Jurnal Ilmiah SEMANTIKA, Volume 2, No. 01, Agustus 2020, p. 36-43

\section{Data, Instrument, dan Teknik Pengumpulan Data}

Data yang digunakan sebagai fakta empirik yang digunakan oleh peneliti sebagai pemecah masalah dalam penelitian dari data awal (pretest) mahasiswa mata kuliah apresiasi dan kajian drama dan nilai akhir (posttest) pada mata kuliah apraesiaisi dan kajian drama. Instrumen yang digunakan pada penelitian bermacam-macam, diantaranya:

1. Tes

Tes diberikan untuk mengetahui kemampuan mahasiswa pada mata kuliah apresiasi dan kajian drama berbasis kebudayaan Brebes. Tes diberikan pada awal atau sebelum diberi perlakuan dan pada akhir setelah diberi perlakukan.

2. Angket

Angket pada penelitian ini diberikan dengan tujuan untuk memperoleh tanggapan dari mahasiswa tentang bahan ajar "Apresiasi dan Kajian Drama Berbasis Kebudayaan Brebes" berupa buku yang telah diberikan. Hal tersebut dengan tujuan sebagai tolok ukur sejauh mana bahan ajar dapat dimanfaatkan oleh mahasiswa.

3. Dokumentasi

Dokummentasi dalam penelitian ini digunakan untuk mencatat dan merekam peristiwa penelitian dari awal hingga akhir penelitian. Dokumen penelitian ini berupa catatan-catatan penting dan gambar-gambar saat penelitian berlangsung.

Teknik pengumpulan data pada penelitian ini dapat dijelaskan sebagai berikut:

a. Memberikan Pretest

Pada langkah teknik pengumpulan data ini, mahasiswa pendidikan bahasa dan sastra Indonesia diberikan soal-soal yang berkaitan dengan materi apresiasi dan kajian sastra. Tujuannya adalah untuk mengetahui kemampuan awal mahasiswa sebelum dilkakukan (treament) dengan menggunakan bahan ajar (berupa buku) apresiasi dan kajian drama.

b. Memberikan Perlakukan (treatment)

Pada langkah berikutnya dengan perlakuan (treatment) setelah mahasiswa menyelesaikan pretest. Pada teknik pengumpulan data ini, perkuliahan dengan menggunakan bahan ajar (buku) apresiasi dan kajian drama berbasis kebudayaan Brebes sebagai bentuk perlakuan kepada mahasiswa.

c. Memberikan posttes

Pada langkah pengambilan data ini, mahasiswa diberikan tes akhir (posttes) dengan tujuan untuk mengetahui perbandingan kemampuan mahasiswa setelah mengikuti mengikuti perkuliahan dengan menggunkan bahan ajar apresiasi dan kajian drama berbasis kebudayaan Brebes dengan sebelumnya. Soal yang diberikan pada posttes tidak jauh berbeda dengan soal pretest.

d. Memberikan Angket

Angket diberikan setelah dilakukan posttes kepada sejumlah mahasiswa yang sama dengan tujuan untuk mengetahui tanggapan-tanggapan terhadap bahan ajar apresiasi dan kajian drama berbasis kebudayaan Brebes.

\section{Teknik Analisis Data}

Teknik analisis data pada penelitian ini menggunakan uji normalitas data, uji homogenitas data, dan uji hipotesis keefektifan produk. Selanjutnya dapat dijelaskan sebagai berikut:

a. Uji Normalitas data

Uji normalitas data digunakan dengan tujuan untuk mengetahui data sampel berasal dari populasi yang berdistribusi normal atau tidak. Untuk menguji kenormalan data digunakan SPSS.

b. Uji Homogenitas Data

Uji homogenitas data digunakan dengan tujuan untuk menguji data sampel yang diambil homogen atau tidak dari populasi yang sama. Untuk menguji data sampel digunakan uji Levene's Test yang adadi dalam SPSS.

c. Uji Hipotesis Data

Setelah melakukan uji syarat (Uji normalitas dan homogenitas), tahap selanjutnya melakukan uji hipotesis Data. Nilai mahasiswa data dari pretest dan posttes diolah menggunakan SPSS untuk memperoleh nilai signifikansi pada independent sample test. 


\section{HASIL DAN PEMBAHASAN}

\section{Hasil Penelitian}

Hasil penelitian ini terdiri dari 2 aspek yaitu data nilai mata kuliah apresiasi dan kajian drama berbasis kebudayaan Brebes dan data keefektifan bahan ajar apresiasi dan kajian drama berbasis kebudayaan Brebes. Berikut penjelasan dua aspek tersebut.

a. Data Nilai Mahasiswa Mata Kuliah Apresiasi dan Kajian Drama Berbasis Kebudayaan Brebes

Data nilai mahasiswa mata kuliah apresiasi dan kajian drama terdiri atas data nilai awal (pretest) dan nilai akhir (posttes). Perolehan data nilai tes awal (pretest) diperoleh dari tes yang diberikan kepada mahasiswa sebelum mendapatkan perlakuan (treatment) dengan menggunakan buku ajar apresiasi dan kajian drama berbasis kebudayaan Brebes. Nilai mata kuliah apresiasi dan kajian drama pada tes awal (pretest) kelas eksperimen mahasiswa program studi pendidikan bahasa dan sastra Indonesia Universitas Muhadi Setiabudi berbentuk data nilai awal mahasiswa. Berdasarkan hasil analisis dapat dikemukakan bahwa hasil tes awal (pretest) sebelum mendapatkan perlakuan (treatment) terhadap 25 mahasiswa yaitu skor terendah 63 dan skor tertinggi 82. Dari data tersebut ada 23 mahasiswa yang belum tuntas. Hal tersebut dibuktikan dengan perolehan nilai apresiaisi dan kajian drama dengan rentang 75 - 82 sebanyak 2 mahasiswa, perolehan nilai rentang 65 - 74 sebanyak 13 mahasiswa dan 00 - 64 sebanyak 10 mahasiswa.

Selanjutnya, data nilai mata kuliah apresiasi dan kajian drama pada tes akhir (posttes) kelas eksperimen diperoleh dengan menggunakan buku ajar apresiasi dan kajian drama berbasis kebudayaan Brebes. Buku ajar tersebut dapat dilihat pada gambar 1 berikut ini.
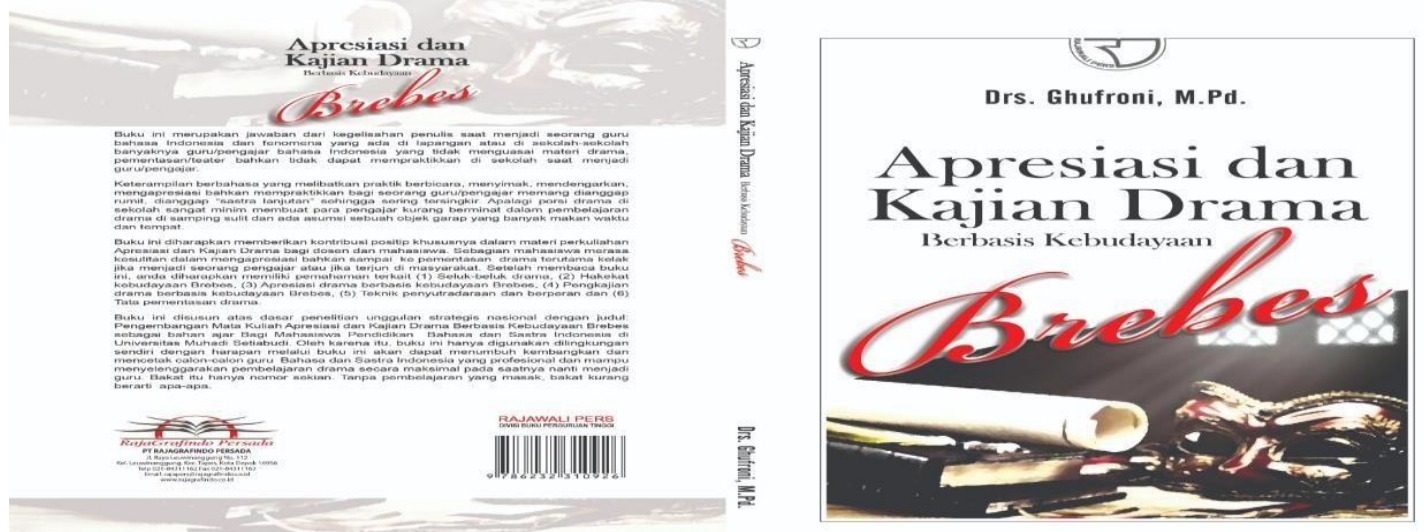

\section{Gambar 1. Buku ajar Apresiasi dan Kajian Drama Berbasis Kebudayaan Brebes}

Setelah mahasiswa mendapatkan perlakukan (treatment) dengan menggunakan buku ajar apresiasi dan Kajian Drama berbasis Kebudayaan Brebes, selanjutnya diperoleh nilai tes akhir (posttes) mata kuliah apresiasi dan Kajian drama. Berdasarkan hasil analisis data, dapat dikemukakan bahwa hasil tes akhir (posttes) mata kuliah apresiasi dan Kajian drama dengan menggunakan buku ajar apresiasi dan kajian drama berbasis kebudayaan Brebes sudah memenuhi ketuntasan perkuliahan dengan skor nilai terendah 75 dan skor tertinggi 90. Dengan demikian dapat dikatakan bahwa hasil tes akhir dinyatakan tuntas semua. Hal tersebut dibuktikan dengan pencapaian nilai tes mata kuliah apresiasi dan kajian drama dengan rentang nilai 75 - 84 sebanyak 15 mahasiswa dan 85 - 100 sebanyak 10 mahasiswa.

b. Keefektifan Buku Ajar Apresiasi dan Kajian Drama Berbasis Kebudayaan Brebes

Keefektifan buku ajar apresiasi dan kajian drama berbasis kebudayaan Brebes terdiri atas uji normalitas data, uji homogenitas data, dan uji hipotesis data. Berdasarkan hasil analisis data uji normalitas menggunakan Shapiro - Wilk yang diperoleh signifikansi sebesar 0,075 lebih besar dari 0,05 (signifikansi yang digunakan), maka ha ditolak dan ho diterima. Yang berarti data tersebut berdistribusi normal.

Setelah dilakukan uji normalitas data, selanjutnya dilakukan uji homogenitas data 
Jurnal Ilmiah SEMANTIKA, Volume 2, No. 01, Agustus 2020, p. 36-43

untuk memperoleh hipotesis data dengan menggunakan independent sample test. Berikut hasil perhitungannya pada tabel 1 .

Tabel 1. Independent Sample Test

\begin{tabular}{|c|c|c|c|c|c|}
\hline & \multicolumn{2}{|c|}{ Levene's Test } & \multicolumn{3}{|c|}{ t-test for Equality of Means } \\
\hline & $\begin{array}{l}\text { for } \\
\text { of } \mathrm{Va}\end{array}$ & \multicolumn{3}{|c|}{ of Variances } & \\
\hline & $\mathrm{F}$ & Sig. & $\mathbf{t}$ & df & $\begin{array}{l}\text { Sig. (2- } \\
\text { tailed) }\end{array}$ \\
\hline Nilai & & & & & \\
\hline $\begin{array}{l}\text { Equal } \\
\text { variances } \\
\text { assumed }\end{array}$ & 2.00 & 0.075 & 8.776 & 48 & .000 \\
\hline Nilai & & & & & \\
\hline $\begin{array}{l}\text { Equal } \\
\text { variances }\end{array}$ & & & 8.776 & 47.024 & .000 \\
\hline not & & & & & \\
\hline assumed & & & & & \\
\hline
\end{tabular}

Berdasarkan hasil analisis data terlihat $\mathrm{t}$ hitung $=8,776$ sedangkan $\mathrm{t}$ tabel $=2,00$. Artinya $\mathrm{t}$ hitung $>\mathrm{t}$ tabel, hal ini berarti Ho diterima. Jadi ada pengaruh antara variabel bebas dengan tingkat kepercayaan $95 \%$ atau $\alpha=5 \%$ dengan $(\mathrm{df})=48$. Oleh karena itu dapat disimpulkan bahwa terdapat perbedaan yang signifikan antara rata-rata nilai mahasiswa pretes dan posttes kelas eksperimen dengan menggunakan buku ajar. Dapat dikatakan bahwa buku ajar apresiasi dan kajian drama berbasis kebudayaan Brebes dapat meningkatkan kemampuan mahasiswa PBSI Universitas Muhadi Setiabudi Brebes khususnya pada mata kuliah apresiasi dan kajian drama.

\section{Pembahasan}

Peningkatan kemampuan belajar mahasiswa dan ketuntasan mata kuliah apresiasi dan kajian drama ditunjang dari beberapa faktor. Faktor tersebut diantaranya bahan ajar. Dosen harus mampu mengembangkan bahan ajar diperguruan tinggi masing-masing salah satunya bahan ajar berupa buku. Hal tersebut karena buku ajar efektif dalam meningkatkan kemampun mahasiswa. Sesuai dengan yang dikemukakan oleh Arsanti (2018), Harijanto (2007), dan Oka (2017) bahwa buku ajar dapat memudahkan mahasiswa dalam mempelajari mata kuliah tertentu. Sehingga kemampuan mahasiswa pun bisa meningkat. Kemampuan mahasiswa bukan hanya ditekankan dalam kemampuan pedagogik saja. Namun juga harus seimbang dengan kemampuan afektif.

Afektif mahasiswa tercermin dalam ruang lingkup kelas pada saat perkuliahan. Namun, mahasiswa harus mencerminkan kemampuan afektif bukan hanya sebatas ruang lingkup kelas.Tetapi juga harus mencerminkan dalam kehidupan sehari-hari di masyarakat. Sikap mahasiswa bertolok ukur pada tata norma yang ada pada masyarakat. Norma-norma yang berlaku biasanya tradisi dari leluhur daerah tersebut. Salah satu contoh tradisi atau warisan luhur yang masih kental yaitu kebudayaan Brebes. Masyarakat Brebes khususnya generasi muda pada zaman sekarang kurang memegang norma leluhur yang ada. Hal tersebut berdampak pada nilai- nilai atau perilaku keburukan generasi muda yang merajalela, yang sudah tidak memperhatikan norma budaya. Hal tersebut harus ditangani dengan serius, karena generasi muda harus ditanamkan nilai-nilai kebudayaan Brebes. Salah satu cara cara penanaman budaya dengan mengintegrasikan dalam pembelajaran sesuai dengan pendapat Winarto (2016) [11], Lestariningsih (2017 [12\} dan Ferdianto (2018) [13] bahwa dengan mengintegrasikan kebudayaan Brebes dalam pembelajaran di kelas maka akan menggugah mahasiswa tentang keasadaran pentingnya kebudayaan Brebes. Nilai-nilai luhur yang perlu dilestarikan oleh mahasiswa pada khususnya. 


\section{SIMPULAN}

Penelitian ini menggunakan buku ajar apresiasi dan kajian drama berbasis kebudayaan Brebes pada mahasiswa PBSI (Pendidikan Bahasa dan sastra Indonesia). Berdasarkan data nilai awal bahwa banyak mahasiswa yang belum tuntas. Namun setelah diberi perlakuan dan diberi tes akhir, semua mahasiswa bisa tuntas dalam mata kuliah tersebut. Uji keefektifan dilakukan dengan beberapa uji yaitu uji normalitas data, uji homogenitas, dan uji hipotesis. Berdasarkan tabel pengolahan data menggunakan SPSS dapat diketahuibahwa data nilai awal (pretest) dan data nilai akhir (posttest) berdistribusi normal dan homogen. Setelah itu dilakukan uji syarat (uji normalitas data dan homogenitas data), tahap selanjutnya yaitu uji hipotesis. Uji hipotesis menggunakan independent samples test dalam SPSS. Berdasarkan hasil uji yang dilakukan menyatakan bahwa adanya perbedaan signifikan hasil pretest dan posttest pada mahasiswa PBSI UMUS. Nilai t hitung lebih besar dari nilai t tabel. Sehingga dapat disimpulkan bahwa bahan ajar efektif diterapkan dalam perkuliahan apresiasi dan kajian drama.

\section{REFERENCES}

[1] F Amalia dan R Kustijono, "Efektifitas Penggunaan E-Book dengan Sigil untuk Melatih Kemampuan Berpikir Kritis," SNF FMIPA UNESA, 81-85, 2017, [Online]. https://fisika.fmipa.unesa.ac.id/prosedings/index.php/snf.article.view/42

[2] Arina Manasikana, Agung Listiadi, "Pengembangan Bahan Ajar Interaktif Berbasis Android Pada Materi Jurnal Penyesuaian dan Jurnal Koreksi Untuk Kelas XII Akuntansi di SMK N 1 Surabaya", Jurnal Pendidikan Akuntansi, Vol. 5, No. 2, 1 - 8, 2017, [Online]. https://jurnalmahasiswa.unesa.ac.id/index.php/jpak/article/view/21225/19462

[3] Rusman, Strategi dan Model Pembelajaran, 2014, Rajawali Pers. PT Raja GrafindoPersada, Jakarta.

[4] Edi Suryanto, Budi Waluyo, dan Suyitno, "Kajian Struktural dan Pendidikan Karakter Naskah Drama Panembahan Reso Karya W.S Rendra untuk Pengembangan Mata Kuliah Apresiasi dan Kajian Drama", Proceding Nasional Inovasi Pendidikan, 249-264. 2016, [Online]. http://jurnal.fkip.uns.ac.id/index.php/snip/article/view/8941

[5] Peraturan Daerah Kabupaten Brebes, Rencana Pembangunan Jangka Panjang Kabupaten Brebes 2005-2025, RJPD Pemda Brebes, 1-128. [Online]. file:///C:/Users/acer/AppData/Local/Temp/RPJPD\%20Kab\%20Brebes\%202005\%20\%202025\%20GABUNGAN-1.pdf

[6] Muh. Fahrurrozi, "Pembelajaran Berbasis Budaya", Prosiding Seminar Nasional dan Call Papers Pendidikan karakter dalam pembelajaran bisnis dan manajemen, 1-11. 2015. [Online]. http://digilib.mercubuana.ac.id/manager/t!@ file artikel abstrak/Isi_Artikel 874829613 056.pdf

[7] Septiana Sulastri, "Keefektifan bahan ajar Berbasis Kearifan Lokal Sebagai Penunjang Mata Kuliah Kajian Fiksi”, Cakra Linguista, Volume 2, Nomor 1, 2019, 1-8, 2019. [Online]. https://journal.stkipsingkawang.ac.id/index.php/Cling/article/view/1288/1028

[8] Melian Arsanti, "Pengembangan Bahan Ajar Mata Kuliah Penulisan Kreatif Bermuatan nilai-nilai Karakter Religius Bagi Mahasiswa Prodi PBSI, FKIP, Unissula" Kredo, Volume $1, \quad$ Nomor 2, 71-90, 2018. [Online]. https://journal.stkipsingkawang.ac.id/index.php/Cling/article/view/1288/1028

[9] Pamela Mikaresti, Yusra D, "Pengembangan Bahan Ajar Mata Kuliah Drama Dengan Pendekatan Berbasis Masalah", Pena, Volume 7, Nomor 2, 71-81, 2018. [Online]. https://online-journal.unja.ac.id/index.php/pena/article/view/5314 
[10] Nurul khasanah, Yusuf Suryana, Ahmad Nugraha, "Pengaruh Metode Eksperimen Terhadap Pemahaman Siswa Tentang Gaya Dapat mengubah Gerak Suatu Benda, Pedadidaktika, Volume 5, Nomor 1, 127-139, 2018. [Online]. https://ejournal.upi.edu/index.php/pedadidaktika/article/view/7257/0

[11] Winarto "Pengembangan Model Wisata Pendidikan Berbasis Kearifan Lokal Dengan Pendekatan Saintifik di Brebes Selatan Sebagai alternatip Model Belajar Siswa Sekolah Dasar". Jurnal Dialektika, Volume 6, Nomor 2, 32 - 47, 2016. [Online]. https://journal.peradaban.ac.id/index.php/jdpgsd/article/view/6/4

[12] Lestariningsih, Novi \& Siti Partini Suardiman, "Pengembangan Bahan Ajar TematikIntegratif Berbasis Kearifan Lokal Untuk Meningkatkan Karakter Peduli dan tanggungjawab", Jurnal Pendidikan Karakter, Tahun VII, Nomor 1, 86 - 99, 2017. [Online].

https://journal.uny.ac.id/index.php/jpka/article/view/15503/9695

[13] Ferdianto, Fery, Setiayani, "Pengembangan Media Pembelajaran Berbasis Kearifan Lokal Mahasiswa Pendidikan Matematika, JNPM (Jurnal nasional Pendidikan Matematika, Volume 2, Nomor 1, $37 \quad-\quad 47,2018 . \quad$ [Online]. http://jurnal.unswagati.ac.id/index.php/JNPM/article/view/781/678 